\title{
Development of yield forecast model using multiple regression analysis and impact of climatic parameters on spring wheat
}

\author{
Purbasha Mistry ${ }^{1}$, Ganesh Bora ${ }^{2 *}$ \\ (1. Natural Resources Management, North Dakota State University, Fargo, ND 58102, USA; \\ 2. Agricultural and Biological Engineering Department, Mississippi State University, Starkville, MS 39762, USA)
}

\begin{abstract}
Understanding the impacts of climate change in agriculture is important to ensure optimal and continuous crop production. The agricultural sector plays a significant role in the economy of Upper Midwestern states in the USA, especially that of North Dakota (ND). Spring wheat contributes most of the wheat production in ND, which is a major producer of wheat in the USA. This study focuses on assessing possible impacts of three climate variables on spring wheat yield in ND by building a regression model. Eighty-five years of field data were collected and the trend of average minimum temperature along with average maximum temperature, average precipitation, and spring wheat yield was analyzed using Mann-Kendall test. The study area was divided into 9 divisions based on physical locations. The minimum temperature plays an important role in the region as it impacts the physiological development of the crops. Increasing trend was noticed for 6 divisions for average minimum temperature and average precipitation during growing season. Northeast and Southeast division showed the strongest increasing trend for average minimum temperature and average precipitation, respectively. East-central division had the most decreasing trend for average maximum temperature. A significant relationship was established between spring wheat yield and climatic parameters as the $p$-value is lower than 0.05 level which rejects the null hypothesis. The regression model was tested for forecasting accuracy. The percentage deviation of error for the model is approximately $\pm 30 \%$ in most of the years.
\end{abstract}

Keywords: yield, forecast modelling, multiple regression, climatic parameters, spring wheat DOI: $10.25165 /$ j.ijabe.20191204.4477

Citation: Mistry P, Bora G. Development of yield forecast model using multiple regression analysis and impact of climatic parameters on spring wheat. Int J Agric \& Biol Eng, 2019; 12(4): 110-115.

\section{Introduction}

Agriculture contributes substantially to many parts of the world's economy. Understanding the direct and indirect climate change impacts on the yield of agricultural crops is of great significance. There are several controllable factors such as fertilizer application, farming management practices, genetic composition of grains, and other external factors that affect the crop's yield highly. Besides these, the climatic factors are also responsible for changes in crop production. The climatic factors are at least roughly 32\%-39\% responsible for the crop's yield globally ${ }^{[1]}$. The wheat yield can vary in differential climatic condition based on the geographic location ${ }^{[2]}$. Climatic factors include precipitation, temperature, atmospheric humidity, solar radiation, wind velocity, atmospheric gases, etc. Temperature, precipitation, and solar radiation are the most important factors which influence the agricultural yield by affecting growth, development stages, and productivity of crops ${ }^{[3]}$.

Wheat is the most grown crop of North Dakota (ND), an Upper Midwestern state in the USA. It is produced in all the counties of ND. Almost $90 \%$ of the ND's total land area accounts for farms

\section{Received date: 2018-06-19 Accepted date: 2018-12-14}

Biographies: Purbasha Mistry, Former Graduate Research Assistant, research interest: climate change and ecosystem science, Email: purbasha.mistry@ gmail.com.

*Corresponding author: Ganesh Bora, Associate Professor, research interest: precision agriculture, data management, and sensor applications. 150 Agricultural and Biological Engineering, Mississippi State University, Mississippi State, MS 39762, USA. Tel: +1-662-325-3155, Fax: +1-662-3253853, Email: gcbora@abe.msstate.edu. and ranches and most of those acres are planted in wheat ${ }^{[4]}$. ND ranks first in wheat production contributing as the leading wheat producer in the USA ${ }^{[5]}$. Three types of wheat are mainly grown in ND. They are spring wheat, durum wheat, and winter wheat. In total the state accounts for about 30,300 farms, with an average of 1,300 acres $\left(526 \mathrm{hm}^{2}\right)$ each. Approximately 19,200 ND farms grow wheat. Among the wheat farmers in ND, 74\% grow spring, $25 \%$ raise durum, and $1 \%$ produce winter wheat ${ }^{[5]}$. According to the North Dakota Wheat Commission, approximately 100 nations around the world have imported hard red spring and durum wheat from the state since 2011. The consistent production of wheat is necessary to meet the food demand of the growing population. Meanwhile, the quality of wheat produced is also dependent upon the climatic conditions. Mild summer with frequent rains is most favorable climate for growth of healthy wheat plants, while extreme heat and dry conditions have negative effects on wheat growth. Due to differential climatic condition, the wheat production rate in ND varies between counties. Favorable temperature, frequent rainfall, rich soil moisture, perfect amount of solar radiation is some of the major climatic factors that have impacts on the spring wheat yield of the state. Spring wheat grows best in the climatic condition where summers are mild and not too hot for young plants. For this reason, ND, Montana, South Dakota, and Minnesota are the biggest producers of spring wheat in the USA. In the past, the state has experienced significant losses of crops due to drought and increase in crops pests, and also received some favorable years with a very high yield of crops. This has occurred because of the differential weather condition affecting the economic sector of the state. If farmers are aware of the future impacts of climate change in 
agricultural sector, it is possible to implement strategies beforehand to avoid serious damage when the impact is negative. Similarly, advantages can be taken of the positive climate impact on agricultural production ${ }^{[6]}$.

Since any effect in the agricultural production will directly impact the food demand worldwide for the growing population, it is important to study the possible impacts of climate change on agriculture and focus on adaptive measures to ensure long-term food security. Additionally, the outcome of the study can provide useful insights regarding climate change impacts on agriculture in a similar context.

\section{Objective}

The main goal of this study is to assess the possible impacts of three primary climate variables: (1) minimum temperature, (2) maximum temperature, and (3) precipitation on the yield of spring wheat in ND. The specific objectives are:

a) To assess the changes and trends of average minimum temperature, average maximum temperature, average precipitation and spring wheat yield for the time period 1929-2014.

b) To predict the spring wheat yield by building a model.

c) To estimate the accuracy of the model for forecasting.

\section{Data collection and site selection}

The spring wheat yield data were collected from the website of U.S. Department of Agriculture (USDA): National agricultural statistics service (NASS) ${ }^{[7]}$. Data for the 9 climatic divisions of ND on average precipitation, average minimum temperature, and average maximum temperature were collected from the National Oceanic and Atmospheric Administration (NOAA) through National Environmental Satellite, Data and Information Service $(\mathrm{NESDIS})^{[8]}$. Eighty-five year's data were assessed statistically starting from the year 1929 to 2014.

ND is divided into 9 divisions based on their climate and geographical location. The 9 Climate Divisions of ND are namely Northwest (division 1), Northcentral (division 2), Northeast (division 3), West-central (division 4), Central (division 5), East-central (division 6), Southwest (division 7), Southcentral (division 8), and Southeast (division 9) region. The information on the different climatic division of ND is also been retrieved from the primary website of $\mathrm{NOAA}^{[8]}$. Changes in average precipitation, minimum temperature, and maximum temperature in the time period of 1929 to 2014 were collected and analyzed. Growing season of spring wheat in ND starts from April and ends in September. April is the month when the planting of spring wheat starts. However, the temperature and the growth rate in April is very low, so the planting of wheat sometimes extends till May. June and July are the peak months where the growth of wheat occurs and eventually comes to maturity. Spring wheat is harvested from mid-August to mid-September. Only the climate of growing season is taken into consideration.

\section{Statistical analysis}

Basic statistical analysis was conducted for east and west regions of ND to find out the mean, standard error of mean, standard deviation, minimum and maximum value of the variables. The changes of the specific climatic parameters were assessed using the Mann-Kendall test to observe the trends. Mann-Kendall test can be used to examine whether there is an upward or downward trend in data collected over a time period ${ }^{[9]}$. The statistical software MINITAB version 17 was used to conduct the test.

Mann-Kendall test has been used previously in many climatologic and in hydrologic time-series studies ${ }^{[10]}$. The test is used to assess consistently upward or downward trend in datasets even if the trend is not linear, mainly finds out if the slope of the estimated linear regression line different from zero. In Mann-Kendall test, it takes $X_{1}, X_{2} \ldots ., X_{\mathrm{n}}$ be the set of data points observed at time $T_{1}, T_{2} \ldots ., T_{\mathrm{n}}$, and let the corresponding Mann-Kendall statistics be $S$. For a pair $\left(X_{i}, X_{j}\right)$, it is positive, neutral or negative if $\left(X_{i}, X_{j}\right)$ is greater than 0 , equal to 0 , and less than 0 , respectively. Then $S$ is the difference between the number of positive and the number of negative pairs. In this test, the data does not need to be normally distributed.

Regression models used in predicting crop yield associated with known statistical limitations such as co-linearity between predictor variables and assumptions of past relationships will continue in the future despite the change in management practices $^{[11]}$. In this study, a multiple linear regression analysis is performed to find a correlation between the climatic conditions and the yield of spring wheat. The climatic divisions of ND are divided into two regions, east and west for carrying out regression. Division 2, 3, 5, 6, and 9 are considered as east region based on their elevation. Division 1, 4, 7, and 8 make up the western part of the state for higher elevation compared to others.

In regression, the response or dependent variable $(Y)$ relies on the changes of one or two predictor or independent variables $(X)$. The regression model uses the data to determine an equation to represent relationship between $X$ and $Y$. The model can be expressed as:

$$
\gamma=\beta_{0}+\beta_{1} x_{1}+\ldots+\beta_{k} x_{k}+\in
$$

where, $\beta_{0}$ is the intercept of the regression line that is the predicted value for $\mathrm{y}$ when $x=0, \beta_{1} \ldots \ldots \beta_{k}$ is the slope or coefficients of the regression line - the marginal change in $Y$ per unit change in $X$ given that the other variables are constant, $\varepsilon=$ refers to the random error, the error term is assumed to follow a normal distribution with a mean of zero and a constant variation. The regression equation is written as:

$$
Y=\beta_{0}+\beta_{1} X_{1}+\ldots+\beta_{k} X_{k}
$$

where, spring wheat yield is the response variable and the predictor variables are average minimum temperature, average maximum temperature, and average precipitation. The relationship was predicted based on 0.05 significance level.

In addition, this regression model can also be used to predict or forecasts the spring wheat yield for a particular year. Thus, to ascertain the accuracy of the regression model cross-validation is carried out ${ }^{[12]}$. Cross-validation method is a validation technique which can be used to assess the results of regression analysis. This technique helps to estimate the accuracy of the regression model for predicting the future spring wheat yield of ND. In this study, the data set was divided in two groups, parts of data points were selected from the whole dataset (training dataset or estimation data) for model prediction, and the rest data points (testing dataset or prediction data) were used for model verification.

Previous studies show that the average spring wheat yield increases by considerable amount in approximately ten years range, either through an introduction of new variety or new technology or different farming methods ${ }^{[13,14]}$. This pattern also matches with the selected dataset. As a result, ten years' sample data from each division was taken as estimation dataset for cross-validating. Then to verify the regression model, the climatic data for the next 
consecutive years were put in the regression equation to generate the output for the spring wheat yield for the divisions. The predicted spring wheat yield and observed yield were compared. Three sets of data (1981-1990, 1991-2000 and 2001-2014) were taken from the data set which acts as estimation data, and they were used to forecasts the spring wheat yield of the years 1991-1994, 2001-2004 and 2010-2014, respectively.

The predicted yield is calculated using the regression model generated. The difference of yield, percentage deviation of yield (error in predicting yield), and ratio of the yield is calculated as shown below.

Difference of yield $=$ (Predicted spring wheat yield - Actual spring wheat yield)

Percentage $(\%)$ Deviation $=($ Difference of yield $/$ Predicted spring wheat yield) $\times 100$

Ratio $=$ Predicted spring wheat yield /Actual spring wheat yield

\section{Results}

\subsection{Average spring wheat yield in different divisions}

Figure 1 shows the average spring wheat yield in 9 divisions of ND for over 85 years. Division 3, 6, and 9 are the highest producers of spring wheat which comprises the eastern side. Division 4, 7, and 8 are the lowest producers which are present in the western part with higher elevation.

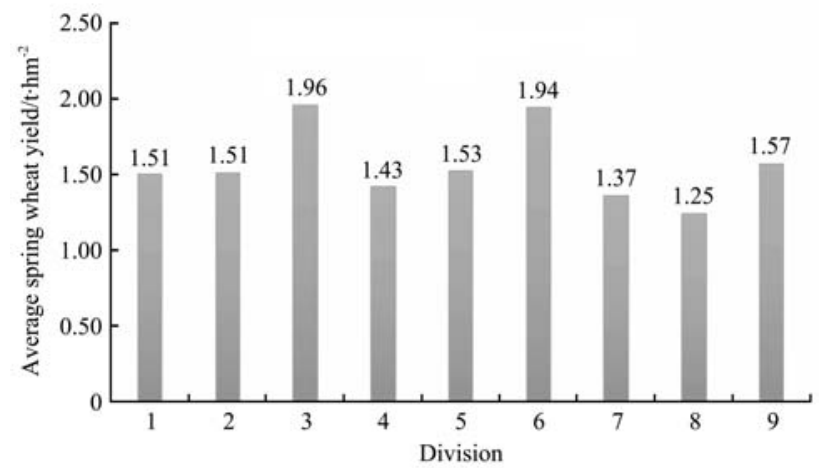

Figure 1 Average spring wheat yield in different divisions of ND

\subsection{Basic statistical analysis}

Table 1 shows the differences in descriptive statistics of the east and the west region of ND. The mean spring wheat yield is 1.70 tons/ha and 1.39 tons/ha for east and west region, respectively. The differences in mean yield indicated that the spring wheat growth is favorable with lower elevation, that is the eastern part of this study. The standard deviation, minimum and maximum value of spring wheat yield is higher for the eastern part.

Table 1 Basic statistics of two regions of North Dakota, USA

\begin{tabular}{ccccccc}
\hline Regions & Variable & Mean & SE Mean & Std. Dev & Minimum & Maximum \\
\hline \multirow{6}{*}{ East } & Wheat yield & 1.70 & 0.04 & 0.85 & 0.17 & 3.94 \\
& Min temp & 7.81 & 0.05 & 0.95 & 5.13 & 10.11 \\
& Max temp & 21.88 & 0.07 & 1.34 & 18.46 & 25.81 \\
& Precipitation & 60.91 & 0.70 & 14.31 & 21.38 & 105.79 \\
\hline \multirow{6}{*}{ West } & Wheat yield & 1.39 & 0.04 & 0.67 & 0.13 & 3.00 \\
& Min temp & 7.48 & 0.05 & 0.83 & 5.22 & 9.59 \\
& Max temp & 22.36 & 0.07 & 1.35 & 18.82 & 25.95 \\
& Precipitation & 53.45 & 0.69 & 12.81 & 16.21 & 89.15 \\
\hline
\end{tabular}

Note: Yield is in the unit of "tons/ha"; Temperature is in the unit of " ${ }^{\circ} \mathrm{C}$ " and Precipitation is in the unit of "cm".

\subsection{Mann-Kendall test analysis}

Table 2, 3, 4, and 5 shows the changes of average minimum temperature, average maximum temperature, average precipitation, and average spring wheat yield respectively for 85 years' time period from 1929 to 2014 in nine divisions of ND. Mann-Kendall test for average minimum temperature reveals that division 4,7 , and 8 has no significant trend at 0.05 significance level. Division $1,2,3,5,6$, and 9 all showed upward trend with p-value lower than 0.05. For average maximum temperature, a downward trend has been established in division $3,5,6,8$, and 9 depicting that the maximum temperature was considerably decreased during the growing season. Division 1, 2, 4, and 7 showed no trend. Null hypothesis has been accepted in this case. It appears that the temperature differences vary with the elevation and geographical location.

In case of average precipitation, division $1,2,3,5,6$, and 9 showed a significant upward trend. Division 4, 7, and 8 showed no significant trend. Division 3 and 6 has the highest Mann-Kendall test statistic. Mann-Kendall test reveals increasing spring wheat yield trend for all the division of ND division demonstrating significant agriculture economic growth since 1929. Division 2, 3, 5, 6, and 9 has the higher value of test statistic compared with others.

Table 2 Mann-Kendall trend test by normal approximation for average minimum temperature data of North Dakota, USA

\begin{tabular}{cccccc}
\hline Division & z-statistic & p-Value & Alpha & Trend & Test interpretation \\
\hline 1 & 1.72 & 0.04 & 0.05 & Upward & Reject $\mathrm{H}_{\mathrm{O}}$ \\
2 & 2.18 & 0.02 & 0.05 & Upward & Reject $\mathrm{H}_{\mathrm{O}}$ \\
3 & 3.02 & 0.001 & 0.05 & Upward & Reject $\mathrm{H}_{\mathrm{O}}$ \\
4 & -0.21 & 0.42 & 0.05 & No trend & Accept $\mathrm{H}_{\mathrm{O}}$ \\
5 & 2.07 & 0.02 & 0.05 & Upward & Reject $\mathrm{H}_{\mathrm{O}}$ \\
6 & 2.97 & 0.002 & 0.05 & Upward & Reject $\mathrm{H}_{\mathrm{O}}$ \\
7 & -0.71 & 0.24 & 0.05 & No trend & Accept $\mathrm{H}_{\mathrm{O}}$ \\
8 & -0.18 & 0.43 & 0.05 & No trend & Accept $\mathrm{H}_{\mathrm{O}}$ \\
9 & 2.13 & 0.01 & 0.05 & Upward & Reject $\mathrm{H}_{\mathrm{O}}$ \\
\hline
\end{tabular}

Note: $\mathrm{H}_{0}=$ There is no trend (Null hypothesis), $\mathrm{H}_{1}=$ There is a trend either upward or downward (Alternative Hypothesis).

Table 3 Mann-Kendall trend test by normal approximation for average maximum temperature data of North Dakota, USA

\begin{tabular}{cccccc}
\hline Division & z-statistic & p-Value & Alpha & Trend & Test interpretation \\
\hline 1 & -0.34 & 0.37 & 0.05 & No trend & Accept $\mathrm{H}_{\mathrm{O}}$ \\
2 & -1.32 & 0.09 & 0.05 & No trend & Accept $\mathrm{H}_{\mathrm{O}}$ \\
3 & -1.65 & 0.04 & 0.05 & Downward & Accept $\mathrm{H}_{\mathrm{O}}$ \\
4 & -0.06 & 0.47 & 0.05 & No trend & Accept $\mathrm{H}_{\mathrm{O}}$ \\
5 & -1.73 & 0.04 & 0.05 & Downward & Reject $\mathrm{H}_{\mathrm{O}}$ \\
6 & -1.72 & 0.04 & 0.05 & Downward & Reject $\mathrm{H}_{\mathrm{O}}$ \\
7 & -0.75 & 0.23 & 0.05 & No trend & Accept $\mathrm{H}_{\mathrm{O}}$ \\
8 & -1.85 & 0.03 & 0.05 & Downward & Reject $\mathrm{H}_{\mathrm{O}}$ \\
9 & -2.11 & 0.02 & 0.05 & Downward & Reject $\mathrm{H}_{\mathrm{O}}$ \\
\hline
\end{tabular}

Table 4 Mann-Kendall trend test by normal approximation for average precipitation data of North Dakota, USA

\begin{tabular}{cccccc}
\hline Division & z-statistic & p-Value & Alpha & Trend & Test interpretation \\
\hline 1 & 1.93 & 0.03 & 0.05 & Upward & Reject $\mathrm{H}_{\mathrm{O}}$ \\
2 & 2.14 & 0.02 & 0.05 & Upward & Reject $\mathrm{H}_{\mathrm{O}}$ \\
3 & 2.72 & 0.003 & 0.05 & Upward & Reject $\mathrm{H}_{\mathrm{O}}$ \\
4 & 1.25 & 0.12 & 0.05 & No trend & Accept $\mathrm{H}_{\mathrm{O}}$ \\
5 & 1.72 & 0.04 & 0.05 & Upward & Reject $\mathrm{H}_{\mathrm{O}}$ \\
6 & 2.91 & 0.002 & 0.05 & Upward & Reject $\mathrm{H}_{\mathrm{O}}$ \\
7 & 0.40 & 0.35 & 0.05 & No trend & Accept $\mathrm{H}_{\mathrm{O}}$ \\
8 & 1.17 & 0.12 & 0.05 & No trend & Accept $\mathrm{H}_{\mathrm{O}}$ \\
9 & 2.16 & 0.02 & 0.05 & Upward & Reject $\mathrm{H}_{\mathrm{O}}$ \\
\hline
\end{tabular}


Table 5 Mann-Kendall trend test by normal approximation for spring wheat yield data of North Dakota, USA

\begin{tabular}{cccccc}
\hline Division & z-statistic & $p$-Value & Alpha & Trend & Test interpretation \\
\hline 1 & 9.00 & 0.00 & 0.05 & Upward & Reject $\mathrm{H}_{\mathrm{O}}$ \\
2 & 9.47 & 0.00 & 0.05 & Upward & Reject $\mathrm{H}_{\mathrm{O}}$ \\
3 & 9.94 & 0.00 & 0.05 & Upward & Reject $\mathrm{H}_{\mathrm{O}}$ \\
4 & 8.96 & 0.00 & 0.05 & Upward & Reject $\mathrm{H}_{\mathrm{O}}$ \\
5 & 9.60 & 0.00 & 0.05 & Upward & Reject $\mathrm{H}_{\mathrm{O}}$ \\
6 & 10.03 & 0.00 & 0.05 & Upward & Reject $\mathrm{H}_{\mathrm{O}}$ \\
7 & 8.13 & 0.00 & 0.05 & Upward & Reject $\mathrm{H}_{\mathrm{O}}$ \\
8 & 8.23 & 0.00 & 0.05 & Upward & Reject $\mathrm{H}_{\mathrm{O}}$ \\
9 & 10.20 & 0.00 & 0.05 & Upward & Reject $\mathrm{H}_{\mathrm{O}}$ \\
\hline
\end{tabular}

\subsection{Regression analysis and cross-validation}

Table 6 shows the regression equation of the two regions of ND generated from performing the multiple regression model. The regression equation explains how the unit changes in the predictor variables give the total yield of spring wheat.
Table 7 and 8 shows the results from the ANOVA table which are obtained from the regression analysis. The residual plots and the normal distribution plot follow a fairly random pattern and normal distribution curve respectively, indicating a good fit for a linear model. The regression model was significant for both the regions as the p-value were lower than $\alpha$. Analyzing each climatic variable of each division, the $p$-values for partial variables were found to be greater than chosen $\alpha$, which indicated that the association is not statistically significant.

Table 6 Multiple regression equation of different regions of North Dakota, USA

\begin{tabular}{cl}
\hline Regions & \multicolumn{1}{c}{ Regression Equations } \\
\hline \multirow{2}{*}{ East } & $\begin{array}{l}\text { Spring Wheat yield=8.266+0.6001Avg. Tmin-0.4845Avg. } \\
\text { Tmax-0.01065Avg. PCP }\end{array}$ \\
\multirow{2}{*}{ West } & $\begin{array}{l}\text { Spring Wheat yield=0.966-0.1568Avg. Tmin+0.0208Avg. } \\
\text { Tmax+0.02111Avg. PCP }\end{array}$ \\
\hline
\end{tabular}

Note: Yield is in the unit of "tons/ha"; Temperature is in the unit of " ${ }^{\circ} \mathrm{C}$ " and Precipitation is in the unit of " $\mathrm{cm}$ ".

Table 7 Regression analysis (east divisions of North Dakota, USA)

\begin{tabular}{|c|c|c|c|c|c|c|c|c|c|}
\hline \multicolumn{5}{|c|}{ Analysis of Variance } & \multicolumn{5}{|c|}{ Parameter Estimates } \\
\hline Source & Sum of Squares & Mean Square & F value & $\mathrm{P}$ value & Variable & Parameter estimate & $\mathrm{T}$ value & $\mathrm{P}$ value & VIF \\
\hline Regression & 71.4 & 23.8 & 42.5 & 0.00 & Constant & 8.27 & 9.09 & 0.00 & \\
\hline Error & 238 & 0.56 & & & Avg. Tmin & 0.60 & 8.52 & 0.00 & 3.4 \\
\hline \multicolumn{5}{|c|}{ Model Summary } & Avg. Tmax & -0.48 & -9.28 & 0.00 & 3.8 \\
\hline S & \multicolumn{2}{|c|}{ R-square } & \multicolumn{2}{|c|}{ R-square (adj) } & Avg. PCP & -0.01 & -2.81 & 0.01 & 2.3 \\
\hline 0.75 & \multicolumn{2}{|c|}{$23.1 \%$} & \multicolumn{2}{|c|}{$22.5 \%$} & & & & & \\
\hline
\end{tabular}

Table 8 Regression analysis (west divisions of North Dakota, USA)

\begin{tabular}{|c|c|c|c|c|c|c|c|c|c|}
\hline \multicolumn{5}{|c|}{ Analysis of Variance } & \multicolumn{5}{|c|}{ Parameter Estimates } \\
\hline Source & Sum of Squares & Mean Square & F value & $\mathrm{P}$ value & Variable & Parameter estimate & T value & $P$ value & VIF \\
\hline Regression & 26.3 & 8.75 & 23.0 & 0.00 & Constant & 0.97 & 0.98 & 0.33 & \\
\hline Error & 129 & 0.38 & & & Avg. Tmin & -0.16 & -1.90 & 0.06 & 4.2 \\
\hline \multicolumn{5}{|c|}{ Model Summary } & Avg. Tmax & 0.02 & 0.36 & 0.72 & 5.6 \\
\hline $\mathrm{S}$ & \multicolumn{2}{|c|}{ R-square } & \multicolumn{2}{|c|}{ R-square (adj) } & Avg. PCP & 0.02 & 5.16 & 0.00 & 2.5 \\
\hline 0.62 & \multicolumn{2}{|c|}{$16.9 \%$} & \multicolumn{2}{|c|}{$16.2 \%$} & & & & & \\
\hline
\end{tabular}

The regression model for the east region indicates significant relationship of average minimum temperature, average maximum temperature, and average precipitation with spring wheat yield. The regression equation indicates that the average minimum temperature is positively related to spring wheat yield. This means that an increase in average minimum temperature will positively contribute to the spring wheat yield. On the other hand, average maximum temperature and average precipitation are found to be negatively related to yield. For the west region, regression model is significant, p-values for both the model and average precipitation were lower than 0.01 . The value for S (standard deviation) is 0.75 and 0.62 for east and west region respectively, in which lower $\mathrm{S}$ value for west region regression interprets better model in describing response. Average precipitation is found to be positively related to yield in western part. Low VIF indicates no multicollinearity existed in the data-set, which is also good for carrying out regression. The VIF value larger than 5 or 10 is an indication that the associated coefficient is likely to be poorly estimated in the regression analysis. In this study, the VIF value is found to be lower than 5 for all the associated coefficients, except for average maximum temperature which is slighter higher than 5 (5.6).
Cross-validation of the regression model for eastern region reveals that the model is significant for two of the three sets. The percentage deviation is approximately around and below 30\% in most of the cases. One or two data exceeded the error above $40 \%$. According to box plots, the variation in percentage deviation is more for division 3 and 6 for the eastern part. Cross-validation of the regression models for western region discloses that in certain years like 2012, 2002, and 1994 the percentage deviation yield is equal to or more than $50 \%$. Other years show reasonably low percentage deviation of yield.

\section{Discussion}

Maximum and minimum temperatures are critical for the spring wheat growth. Like all the other crops, spring wheat also has a temperature limit for their optimal growth condition. Lower minimum temperature negatively affects the survival, cell division, photosynthesis, water transport, growth and consequently yield of the wheat. Higher maximum temperature negatively affects mineral nutrition, shoot growth, pollen development and yield. The increasing trend of average minimum temperature in ND's climate is helpful in promoting optimal growth spring wheat seedlings ${ }^{[15]}$. Consequently, the decreasing trend of average 
maximum temperature evident over 85 years of time in most of the divisions of ND is less damaging for the spring wheat growth. Thus, these changes in the temperature trend can be potentially good for the spring wheat yield.

With increasing trend of temperature, the precipitation is also likely to be increasing. Precipitation in the growing season of spring wheat generally accounts for the total amount of rainfall. With an increased rainfall, the wheat seedlings will have sufficient amount of water and moisture content for their growth. Thus, an upward trend for average precipitation data in the growing season is beneficial for spring wheat production.

From table 2, 3, 4, division 3, 5, 6, and 9 showed a noticeable trend for all the parameters assessed. These divisions mostly comprise the eastern side of the state. Due to the presence of Red River, Devils Lake, and the valley, the eastern side experiences higher humidity compared to the western side. This explains the higher rate of precipitation in the eastern part. Humid weather ensures an increased level of moisture in the air, which is advantageous for the wheat seedlings. From the basic statistical analysis, it is found that the mean spring wheat yield is higher along with higher average minimum temperature, higher average precipitation, and lower average maximum temperature. Thus, increased humidity, minimum temperature, and decreased maximum temperature in the eastern part of ND are demonstrating favorable climate change for the spring wheat growth.

With the help of multiple regression analysis, a significant relationship was determined for the two regions of the state. P-value in the ANOVA table is lower than 0.05 level, which rejects the null hypothesis. It is notable that the eastern part experiences a humid weather in the summer due to its geographical location compared to the west, and in the regression analysis the average precipitation is found to be negatively related to spring wheat yield in eastern region. This can be explained by the fact that excess precipitation in some years can cause hindrance in wheat growth. There are also studies reported that temperature has more impact on wheat growth rather than precipitation ${ }^{[16,17]}$. Hence, the negative relationship of average precipitation with spring wheat yield (eastern region) may also possess little effect on the yield in comparison with the positive effect of decreasing maximum temperature and increasing minimum temperature. On the contrary to the eastern region, the western region regression model indicates a significant positive relationship among average precipitation and spring wheat yield. As the mean precipitation is lower in the west, increasing trend of precipitation is advantageous for wheat produced there.

Cross-validation of regression model provides an intriguing result. The error for predicting spring wheat yield is surprisingly less for certain years. However, years like 1994, 2003, 2004, and 2012 showed higher percentage deviation or error in forecasting. The higher percentage deviation closer to $100 \%$ for 2012 can be justified by the potential influential points as found in Cook's D plot. 1994, 2003, and 2004's percentage deviation is around 50\%. The rest of the year's errors are $30 \%$ and below. The model can be considered moderately good for predicting spring wheat yield and understanding the relationship between spring wheat yield and climatic variability associated with some limitations and uncertainties. Despite some limitations of the statistical model's, it is useful in forecasting the future impacts of climate change ${ }^{[11]}$. Emphasis should be given on the response generated from the model to understand the implications of climate change. Lobell \& Asseng reported no significant differences in the prediction of crop yields due to climate change using process-based and statistical models $^{[18]}$.

The data from environmental studies do not always follow a linear pattern such as a nonlinear relationship between temperature and crop yield ${ }^{[19]}$. The data for climatic parameters shows a very subtle change rather than a drastic one. To quantify the exact and direct impact level of climatic variables on spring wheat yield using statistical analysis is difficult and complex. This study assumed that other factors such as management practices and seed varieties responsible for spring wheat production are kept constant during the analysis. As the production of agricultural crops is not only affected by climatic condition, sometimes it becomes impossible to assess the direct impact of climate change. However, from this study, it is certain that there has been a change in the climatic variables assessed in the study for the past 85 years in ND and that the climatic variables have impact on the production of spring wheat in the region. Farmers can use the information from the study to improve the farming practices by selecting the right crop type (e.g. spring wheat) in changing climate. In addition, adjusting the cultivation time according to the changed climatic pattern can help farmers maximize the crop yield.

\section{Conclusions}

The study was undertaken to assess the change of different climatic parameters and its impact on spring wheat production. An upward trend has been found for average minimum temperature in six divisions and downward trend has been noted in five divisions for average maximum temperature. For average precipitation upward trend is found for six divisions among nine divisions. All the nine-divisions showed strong upward trend for spring wheat yield. Significant relationship has been established using multiple linear regression. The changes in spring wheat growth and trends of climatic condition of the state provided a comprehensive idea about the production rate of spring wheat in coming years. Improved understanding of the impact of climate variability on the spring wheat yield can help regional farmers to adopt sustainable agricultural practices and help them in making appropriate farming management decisions.

\section{Acknowledgement}

The authors acknowledge the Graduate Research Assistantship provided by the Agricultural Experiment Station, North Dakota State University, Fargo, ND, USA for the study period.

\section{[References]}

[1] Ray D K, Gerber J S, MacDonald G K, West P C. Climate variation explains a third of global crop yield variability. Nature Communications, 2015; 6: 5989.

[2] Ortiz R., Sayre, K D, Govaerts B, Gupta R., Subbarao G V, Ban T, Hodson D, Dixon J M, Ortiz-Monasterio J I, Reynolds M. Climate change: can wheat beat the heat? Agriculture, Ecosystems \& Environment, 2008; 126(1-2): 46-58.

[3] Nkeme K K, Ndaeyo N U. Climate change coping strategies among peasant farmers in Akwa Ibom State, Nigeria. International Journal of Basic and Applied Science, 2013; 2(1): 24-28.

[4] United States Department of Agriculture. Agricultural statistics 2009 United States Government Printing Office, Washington, DC, 2009.

[5] North Dakota Wheat Commission. Available: http://www.ndwheat.com/ buyers/default.asp?ID=294. Accessed on [2015-09-21].

[6] McCarthy J J, Canziani O F, Leary N A, Dokken D J, White K S. Climate change 2001: Impacts, adaptation and vulnerability. Cambridge University Press, 2001.

[7] United States Department of Agriculture: National Agricultural Statistics Service. Available: http://www.nass.usda.gov/Quick_Stats/Lite/. 
Accessed on [2015-07-12].

[8] National Oceanic and Atmospheric Administration's (NOAA). National Climatic Data Center. Available: http://www7.ncdc.noaa.gov/CDO/ CDODivisionalSelect.jsp. Accessed on [2015-05-16]

[9] United States Environmental Protection Agency. Data quality assessment: statistical method for practitioners. Office of Environmental Information, Washington, DC. 2006; Available: http://www.epa.gov/quality/qs-docs/ g9s-final.pdf. Accessed on [2015-08-12].

[10] Karmeshu N. Trend detection in annual temperature \& precipitation using the Mann Kendall Test-a case study to assess climate change on select states in the northeastern United States. Master of Environmental Studies Capstone Projects. University of Pennsylvania, USA, 2012, 08.

[11] Lobell D B, Burke M B. On the use of statistical models to predict crop yield responses to climate change. Agricultural and Forest Meteorology, 2010; 150(11): 1443-1452.

[12] Myers R H. Classical and modern regression with applications. Belmont, CA: Duxbury Press, 1990

[13] Smith G S. Changes in North Dakota hard red spring wheat varieties, 1900-1977. North Dakota Farm Research, 1978; 35:16-21.

[14] Gunderson J J, Carr P M., Martin G B. Variety trial yields: a look at the past 65 Years. Technical Report, Dickinson Research Extension Center, North Dakota State University, 2007; Available: http://www.ag.ndsu.edu/ archive/dickinso/research/2007/pdf/agron07a. pdf.

[15] Bora G C, Bali S, Mistry P. Impact of climate variability on yield of spring wheat in North Dakota. American Journal of Climate Change, 2014; 3(4): 366.

[16] Lobell D B, Burke M B. Why are agricultural impacts of climate change so uncertain? The importance of temperature relative to precipitation. Environmental Research Letters, 2008; 3(3): 034007.

[17] Pirttioja N, Carter TR, Fronzek S, Bindi M, Hoffmann H, Palosuo T, Ruiz-Ramos M, Tao F, Trnka M, Acutis M, Asseng S. Temperature and precipitation effects on wheat yield across a European transect: a crop model ensemble analysis using impact response surfaces. Climate Research, 2015; 65: 87-105.

[18] Lobell D B, Asseng S. Comparing estimates of climate change impacts from process-based and statistical crop models. Environmental Research Letters, 2017; 12(1): 015001.

[19] Schlenker W, Roberts M J. Nonlinear temperature effects indicate severe damages to US crop yields under climate change. Proceedings of the National Academy of sciences, 2009; 106(37): 15594-15598. 